\title{
Article
}

\section{Resistance and Consumption Reduction Mechanism of Bionic Vibration and Verification of Field Subsoiling Experiment}

\author{
Deyi Zhou, Pengfei Hou $\mathbb{D}^{\mathrm{D}}$, Yuelin Xin, Baoguang Wu*, Jin Tong, Haiye Yu, Jiangtao Qi $\left(\mathbb{D}\right.$, Jinsong Zhang ${ }^{(D)}$ \\ and Qiang Zhang
}

Citation: Zhou, D.; Hou, P.; Xin, Y.; Wu, B.; Tong, J.; Yu, H.; Qi, J.; Zhang, J.; Zhang, Q. Resistance and

Consumption Reduction Mechanism of Bionic Vibration and Verification of Field Subsoiling Experiment. Appl. Sci. 2021, 11, 10480. https:// doi.org/10.3390/app112110480

Academic Editor: Itzhak Katra

Received: 7 October 2021

Accepted: 5 November 2021

Published: 8 November 2021

Publisher's Note: MDPI stays neutral with regard to jurisdictional claims in published maps and institutional affiliations.

Copyright: (c) 2021 by the authors. Licensee MDPI, Basel, Switzerland. This article is an open access article distributed under the terms and conditions of the Creative Commons Attribution (CC BY) license (https:// creativecommons.org/licenses/by/ $4.0 /)$.
The College of Biological and Agricultural Engineering, Jilin University, 5988 Renmin Street, Changchun 130025, China; zhoudy@jlu.edu.cn (D.Z.); houpf20@mails.jlu.edu.cn (P.H.); meijingaifan@163.com (Y.X.); xinyuelin163@163.com (J.T.); haiye@jlu.edu.cn (H.Y.); qijiangtao@jlu.edu.cn (J.Q.); jluzjs@jlu.edu.cn (J.Z.); zhangqiang@jlu.edu.cn (Q.Z.)

* Correspondence: wubg@jlu.edu.cn

\begin{abstract}
This study proposed a design method for forced-vibration subsoiling to reduce resistance and consumption. The vibration digging parameters of the Antlion larvae were obtained by highspeed camera, and a forced-vibration subsoiling shovel handle and six different shovel tips were designed by the non-smooth resistance-reducing surface design method. The resistance-reducing and consumption-reducing effects were verified in the field subsoiling experiment. The results showed that the resistance of subsoiling gradually decreased with the vibration frequency increasing. This vibration subsoiling method could not only reduce resistance but also reduce the total energy consumption, the resistance reduction rate reached $14.2-21.2 \%$, and the total energy consumption was reduced by $11.2-16.5 \%$. It could achieve the comprehensive subsoiling effect and create the soil conditions with the combination of loose and firmness. The non-smooth surface contributed to the reduction in resistance, and the forward speed had a more negligible effect on the resistance of subsoiling. The results had demonstrated that the combination of high-frequency vibration and non-smooth surfaces helped to reduce the cohesion of the soil, reduce the angle of internal friction in the soil, destroy the water film layer on the contact surface between the soil-touching components and the soil, change the soil flow state, and reduce the adhesion of the interface layer. The design method in this study could not only be applied to the design of vibration resistance reduction in the subsoiler but also had significance for the design of the other soil-contacting components.
\end{abstract}

Keywords: forced-vibration; antlion bionic; resistance reduction; energy consumption reduction; subsoiler

\section{Introduction}

Soil compaction is one of the most severe forms of soil degradation caused by traditional tillage practices, and it refers to the decrease in porosity between soil aggregates [1-3]. The damage of soil compaction on cultivated land, specifically in the form of stunted crop root growth, affects crop growth [4]; the supply chain of water and nutrients in the soil will be broken [5], with the microbial colony imbalance; the number of host organisms, such as earthworms, will decrease [6]. These damages ultimately affect crop production and cause severe economic losses to the world [7]. Crop production loss due to soil compaction was as much as \$1 billion per year in the United States and \$144 million per year in just one agricultural region of Australia [8,9].

Currently, subsoiling operation is one of the most effective methods to solve the soil compaction problem [10-12]. Subsoiling can break the plow plough pan, improve the soil water storage and moisture conservation capacity, and significantly improve crop production [13]. However, due to the large depth of subsoiling operation, the subsoiling resistance is also significant, and it is very easy to form big soil nuclear at the subsoiler shovel tip [14]. This not only leads to increased subsoiling resistance, increased energy 
consumption, and poor subsoiling operation quality but also is easy to cause damage to machines and tools in severe conditions [15]. This problem can be solved by bionics, electroosmosis, and vibration methods [16-18]. The bionic and electro-osmosis approaches are highly dependent on the parameters such as soil type, moisture content, and soil firmness, although they can achieve resistance reduction $[19,20]$. Numerous studies have shown that the vibration resistance reduction effect of the soil-touching component was highly adaptable in different soil environments [21-23].

The vibration subsoiling mechanism can be divided into two types, which are forced vibration and self-excited vibration according to the different vibration sources [24]. A forced vibration subsoiling mechanism needs an additional vibration exciter, generally uses the output shaft of the tractor as the energy source, and transmits the output power to the vibration exciter so that the subsoiler can vibrate with a specific frequency and amplitude. The subsoiler under this type of vibration is rigidly connected with the vibration exciter. Although it can reduce the resistance, it is limited by the mechanical structure, and the frequency is generally low. Moreover, the total energy consumption of subsoiling operations will increase due to the need for the tractor output power as a vibration source [25].

The self-excited vibration subsoiling mechanisms use the resistance in the subsoiling process to excite the vibration of elastic elements on the subsoiling machine to realize the vibration function. Many self-excited vibration subsoiling machines use springs as elastic elements, which do not need to consume extra energy. However, since the excitation of vibration depends on the subsoiling resistance, there are many uncertain factors for the changes of resistance in actual operations; its vibration frequency and amplitude are uncontrollable. Moreover, due to the elasticity of the vibration mechanism, the penetration angle of the subsoiler tip will change during the vibration process, which will increase the subsoiling resistance [26].

As animals in nature have evolved over billions of years, they have exhibited high adaptability to their environment. The challenge of drag reduction in subsoiling was solved by the bionic approach in this study. The antlion larvae, which are good at digging, were taken as the bionic prototype; its vibration excavation characteristics and non-smooth surfaces structure characteristics were applied to the design of the subsoilers. Antlions belong to the Myrmeleontidae, Neuroptera. Additionally, its larvae are one of the few soil animals that are good at drilling holes in the soil by vibration [27-29]. The antlion larvae vibration digging parameters were obtained by a high-speed camera, and these vibration parameters were optimized and applied to the design of subsoilers. According to the nonsmooth surface characteristics of antlions and pangolins, six subsoiler tips were designed. The mode of using a polarized electric motor as a vibration source to achieve forced vibration for subsoiling operation has rarely been studied in the resistance reduction field of agricultural soil-touching components. The vibration source transmitted the vibration energy to the subsoiler in the form of a vibration wave, avoiding the rigid connection between the vibration source and subsoiler. The frequency conversion between $0-133 \mathrm{~Hz}$ could be achieved through the variable frequency governors. The resistance reduction effect of subsoiling operation was verified through the field subsoiling experiment. The results showed that this high-frequency controlled vibration subsoiling could reduce both the resistance and the total energy consumption of subsoiling operations. Additionally, the non-smooth surface design also had a good resistance reduction effect. The vibration resistance and consumption reduction method provided in this study could be applied not only to the design of subsoilers but also had a significant reference for the design of the other soil-touching components.

\section{Theoretical and Computational Models}

\subsection{Theoretical Model Establishment Method}

In this study, the vibration digging characteristics of the antlions were obtained through a high-speed camera. Based on the existing non-smooth surface drag reduction principle of the antlions, the non-smooth surface and vibration drag reduction mechanism 
was analyzed by combining the bionic principle with the analysis of the mathematical model. Based on the experimental and theoretical analysis, the subsoilers combining non-smooth surface and high-frequency controlled vibration were designed. Their drag reduction effects were verified in the field experiments.

\subsection{Antlions Vibration Digging Feature Acquisition}

Antlions are good at making funnel-shaped traps by vibrating digging in sandy soil to trap ants and other prey. Their entire bodies are covered with multi-scale non-smooth surface structures. It has been shown that the non-smooth body surface structures of antlions are beneficial for their rapid entry into the soil [30].

The antlions were collected from Guangdong, China, with an average length of 8.05 $\mathrm{mm}$ and a width of $3.43 \mathrm{~mm}$. The high-speed camera model is Phantom V711, with a shooting frequency of 1000 frames per second and $1200 \times 800$ pixels. The vibration parameters of antlions digging in yellow sand soil, white sand soil, black soil, and glass surface were obtained. Among them, the yellow sandy soil is the natural environment for the survival of antlions, as shown in Figure 1. The antlion was naturally slid down to the center of the soil and began to make holes in the soil, driven by its natural digging disposition. Additionally, the vibratory digging parameters were recorded.
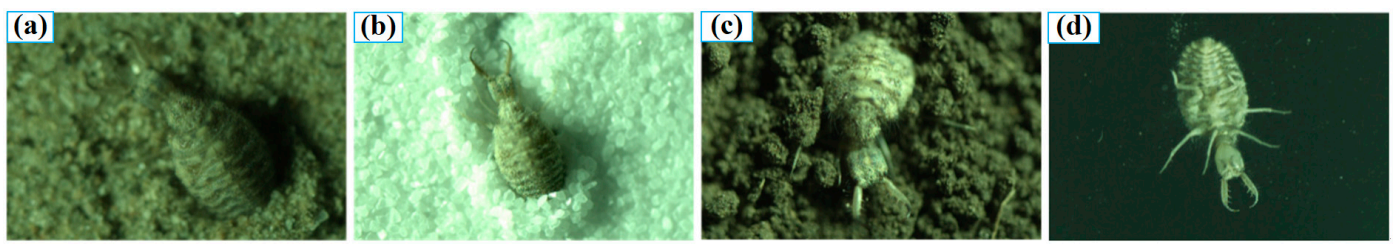

Figure 1. Digging photos of antlions in different conditions: (a) Yellow sandy soil; (b) White sandy soil; (c) Black soil; (d) Glass surface.

Figure 2 shows the whole process of the antlion digging the soil. It dug the soil by vibrating its body. Its vibration was coupled with the up and down vibration of the hindquarters and the vibration of the body swing left and right. The up and down vibration amplitude of the hindquarters was bigger, which was the primary vibration with a slightly lower frequency; the left and right body swinging was an assisted vibration with a higher frequency. These two kinds of vibration were carried out simultaneously during digging.

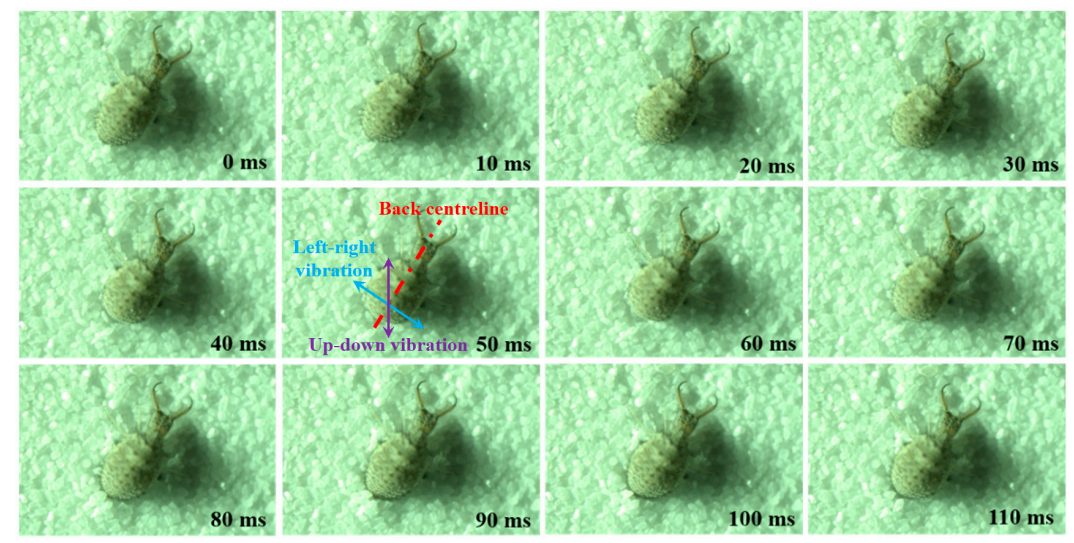

Figure 2. The whole process of soil digging by the antlion.

The whole process of the antlion swinging up and down was recorded as one vibration. Its back had a center line along the body direction, taking this center line as the reference. One swing left and right was recorded as a left and right vibration. The amplitudes and frequencies of the up and down and left-right vibrations of the antlion were recorded in four different states; the processed data were averaged and summarized in Figure 3. 

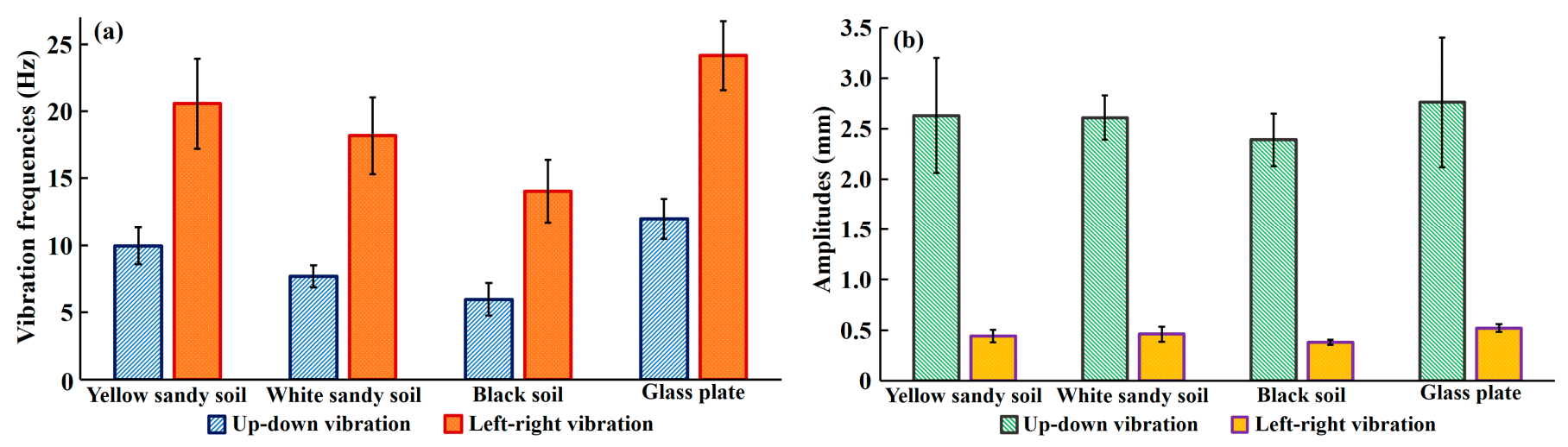

Figure 3. Statistics of the up-down and left-right vibration parameters of the antlions in four conditions: (a) Vibration frequencies; (b) Amplitudes.

While digging, the whole body of the antlions vibrated at a high frequency up and down, left and right, and the amplitude was much bigger than the average particle size of the soil in its living environment, which could produce micro-vibrations in the local area of the soil and help the antlions enter the soil quickly. It is worth pointing out that the self-vibration frequency of dry-clay soil is $20.8-22.6 \mathrm{~Hz}$ and that of clay-sand soil is $21.6 \mathrm{~Hz}$ [31]; the left and right vibration frequencies of the antlions were close to these two, which was a result of natural evolution and helped to reduce the digging resistance of the antlions.

\subsection{Principle and Application of Antlions Digging Resistance Reduction}

It has been shown that the presence of non-smooth structures on the body surface of antlions contributes to its rapid digging. This section analyzed the non-smooth body surface of antlions and the principle of vibration digging to reduce resistance. Based on the principle of drag reduction, the bionic resistance reducing subsoilers were designed.

\subsubsection{Non-Smooth Surfaces and Vibration Resistance Reduction Mechanism}

During digging, the body surface of the antlions came in contact with the soil, and the areas of contact could be divided into five layers. The adhesion between soil and antlion surface depended on the condition of the weakest layer among the five layers [32]. The body surface of the antlion and the soil are simplified to create a contact model, as shown in Figure 4.
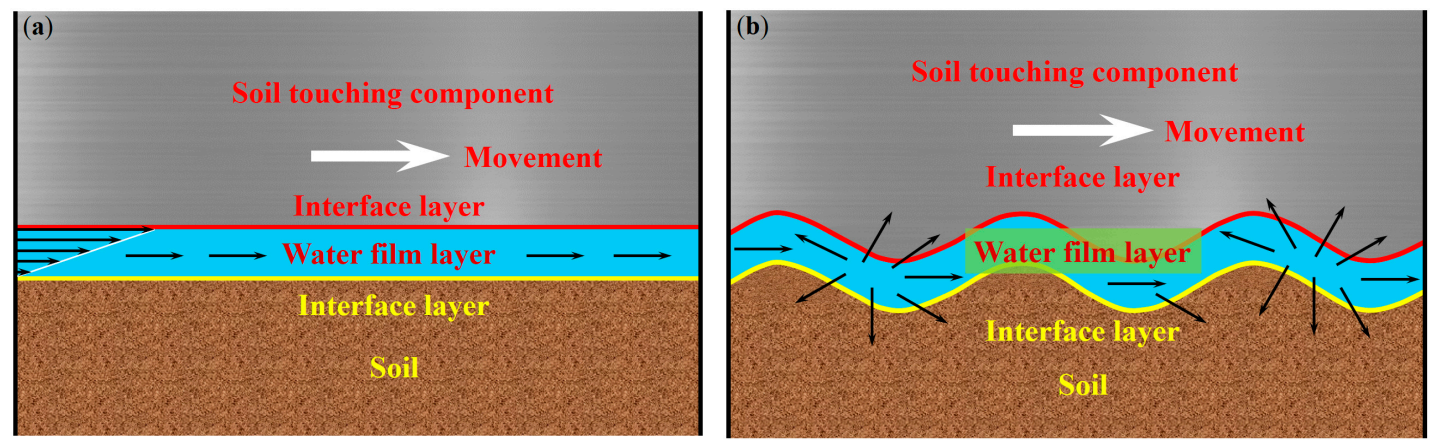

Figure 4. Schematic diagram of five-layer interface model: (a) Smooth surface; (b) Non-smooth surfaces.

Taking $\gamma_{S}$ as the surface free energy of the touching soil component, $\gamma_{L}$ as the surface free energy of soil water, $\gamma_{S L}$ as the free energy of the solid-liquid interface, and $\theta$ as the equilibrium contact angle of soil water on the solid surface.

$$
\gamma_{S}=\gamma_{S L}+\gamma_{L} \cos \theta
$$


The adhesion work $W_{A}$ required to separate the soil-touching component from the soil-water interface per unit area is

$$
W_{A}=\gamma_{S}+\gamma_{L}-\gamma_{S L}=\gamma_{L}(1+\cos \theta)
$$

Considering that there is an adsorbed water vapor layer on the surface of the soiltouching component, its expansion pressure is $\varphi$, so the free energy on the surface of the soil-touching component changes from $\gamma_{S}$ to $\gamma_{S V}$, that is

$$
\gamma_{S V}=\gamma_{S}-\varphi
$$

In this case, the adhesion work required to separate the adhesion interface into two parts, the soil-touching component with water vapor and the soil surface, is denoted as $W_{A}^{\prime}$,

$$
W_{A}^{\prime}=\gamma_{S V}+\gamma_{L}-\gamma_{S L}=\gamma_{S}+\gamma_{L}-\gamma_{S L}-\varphi=\gamma_{L}(1+\cos \theta)-\varphi
$$

Obviously, $W_{A}>W_{A}^{\prime}$, so the typical damage could only occur in the water film layer.

When the contact surface between the soil and the soil-touching components is smooth, the adhesion between the water film layers is larger, and the destructive force is also bigger. When it is a non-smooth surface, the adhesion between the water film layers is destroyed by the non-smooth surface so that the adhesion force at the water film interface changes from anisotropic to isotropic tendency and reduces the resistance to movement.

Vibrational resistance reduction characteristics of antlions could also be analyzed from the perspective of soil shear destruction. The essence of its penetration process is the process of soil shear destruction under the action of external force. The maximum shear stress of soil is an important index of resistance analysis. According to the general expression of the Mohr-Coulomb failure criterion [33]:

$$
\tau=c+\sigma \cdot \tan \varphi
$$

The relationship between the Coulomb shear line and the Mohr circle in static and dynamic shear states was made, and the Mohr circle was simplified to a semicircle, as shown in Figure 5. $\tau$ is the shear stress, $c$ is the cohesion, $\sigma$ is the normal stress, and $\varphi$ is the angle of internal friction. According to the general rule of the Mohr-Coulomb damage criterion, no shear damage occurs in the soil when the Coulomb shear line deviates from the Mohr circle. When they are tangent, it is precisely at the critical position for soil damage; when they are cut, shear damage occurs in the soil [34].

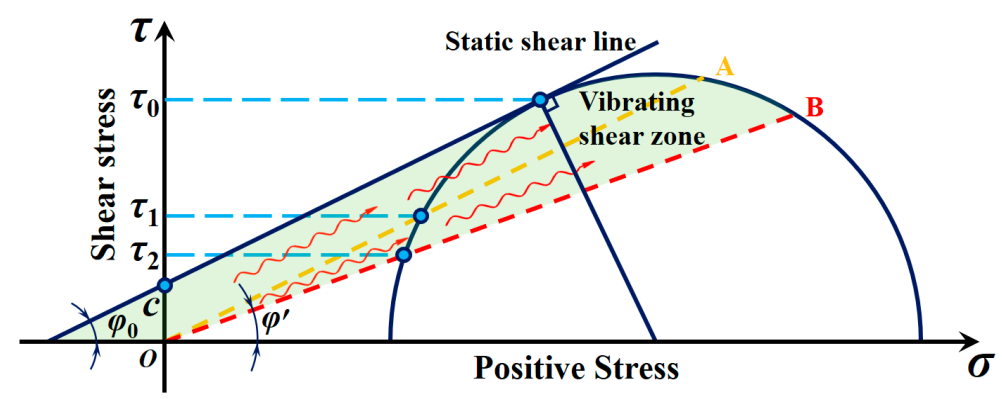

Figure 5. The relationship between Mohr-Coulomb failure criterion and soil vibration shear state.

In the static shear state, a Mohr circle tangent to the shear line is made. At this state, the tangent point between the static shear line and the Mohr circle is the critical point of shear damage, the shear stress is $\tau_{0}$, and the angle of internal friction is $\varphi_{0}$. When the vibration source acts on the soil, the local area where the vibration source is in contact with the soil changes from a solid state to a fluidized state, reducing the cohesion $c$ of the soil in the local area, or the cohesion $c$ even disappears completely, and the local soil changes to a "liquefied" state. At this time, the shear line changes to OA, and the shear 
stress decreases from $\tau_{0}$ to $\tau_{1}$. Further, the vibration is able to change the soil particle size nested state and reduce the internal friction angle of the soil from $\varphi_{0}$ to $\varphi^{\prime}$, the shear line from $\mathrm{OA}$ to $\mathrm{OB}$, and the shear stress from $\tau_{1}$ to $\tau_{2}$. The area enclosed by the static shear line and vibration shear line $\mathrm{OB}$ is the vibration shear zone, and the shear failure of the soil in this area generally has a resistance reduction effect.

Although vibration is able to achieve drag reduction, the vibration source itself consumes extra energy, and the total energy consumed during soil shearing is usually higher than before vibration. The existing vibration subsoiling mechanism connects the rear end of the tractor power take-off shaft to the crank connecting rod, cam, crankshaft, and other structures [35], which produces a vibration effect. This way, the vibration itself produces great energy consumption and increases the total energy consumption while reducing resistance. Additionally, the vibration frequency is low, so the effect of resistance reduction is limited. This study took an electronic vibration motor as the vibration source, which not only produced relatively high vibration frequency but also avoided the rigid connection between the vibration block and soil-contacting components; it could also reduce the total energy consumption during vibration resistance reduction.

\subsubsection{Bionic Drag Reduction Subsoiler Design}

Combined with the principle of bionic non-smooth surface drag reduction and vibration resistance reduction, a vibrating electronic motor forced-vibration subsoiler shovel handle was designed, and six subsoiler shovel tips were designed to verify the resistance reduction effect in the field test (Figure 6). The traction test system is shown in Figure 6a. The vibration source of the forced vibration subsoiler was the electronic vibration motor, which was regulated by PWM (Pulse width modulation) governor, and the frequency variation range was $0-133 \mathrm{~Hz}$ (Figure $6 \mathrm{~b}$ ). The bionic prototypes of non-smooth subsoiler shovel tips in this study were antlion and pangolin. According to the vibration characteristics of antlions, the vibration motor was selected, and two groups of subsoiler shovel tips were designed according to the non-smooth structure of antlion and pangolin scales (Figure 6c). Type $A$, type $B$, and type $C$ subsoiler shovel tips were plane tips, with a shovel surface width of $150 \mathrm{~mm}$ and a shovel tip angle of $60^{\circ}$. Type A shovel tip had a smooth shovel surface, and type $C$ was the control group, which was the bionic pangolin scale shovel tip. Type D, E, and F shovel tips were up-convex curved tips, and other parameters correspond to type A, B, and C one by one (Figure $6 \mathrm{~d}$ ). Among them, the input voltage of the electronic vibration motor was $12 \mathrm{~V}$, and the maximum output power was $60 \mathrm{~W}$.
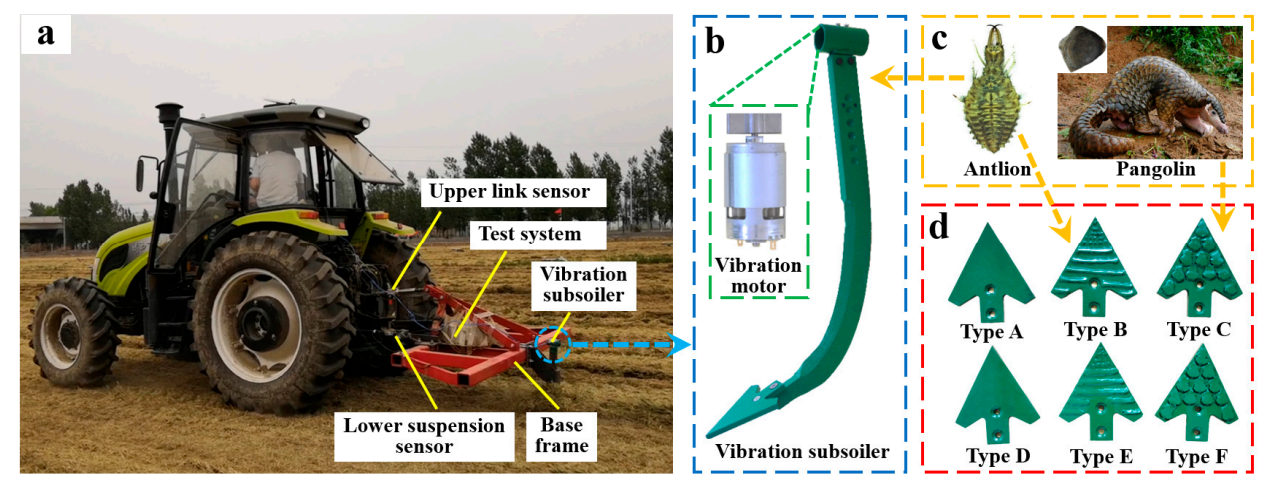

Figure 6. Design of vibrating electronic motor type subsoilers: (a) Traction test system; (b) Vibrating subsoiler; (c) Bionic prototypes; (d) Subsoiler shovel tips.

\section{Field Experiment}

\subsection{Soil Testing}

The soil environment needs to be tested before the experiment, which is an essential factor affecting the subsoiling experiment. The field experiment in this study was carried out at the Dishang Experimental Station, Shijiazhuang, Hebei Province, China (114. $7^{\circ}$ E, 
$37.9^{\circ} \mathrm{N}$ ). Soil moisture content was obtained by a soil moisture sensor (Spectrum TDR 300, America), and ten random sampling points were measured at each soil depth condition. The variation of the soil moisture content with depth in the test field is shown in Figure 7. The average moisture content variation from 0 to $50 \mathrm{~cm}$ depth ranged from 22.8 to $38.8 \%$.

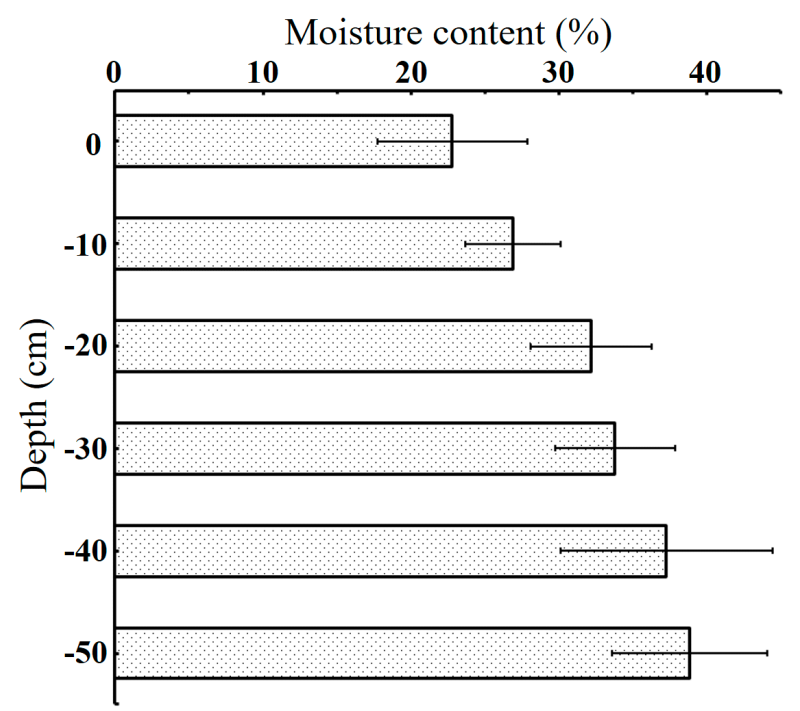

Figure 7. Variation of the soil moisture content with depth.

The laser particle size analyzer (XF3000) was used to test the soil particle size distribution at different depths. Samples were taken at five sampling points, respectively. The test results were averaged to obtain the cumulative mass percentage of the soil particle size distribution, as shown in Figure 8. Among them, particle size less than $2 \mu \mathrm{m}$ is clay soil, $2 \mu \mathrm{m}-20 \mu \mathrm{m}$ is silt soil, and $20 \mu \mathrm{m}-2 \mathrm{~mm}$ is sand soil, and according to the international standard soil type classification [36], the soil in the test area belongs to loam in the depth range of $0-40 \mathrm{~cm}$ and silty loam in the depth range of $40-50 \mathrm{~cm}$.

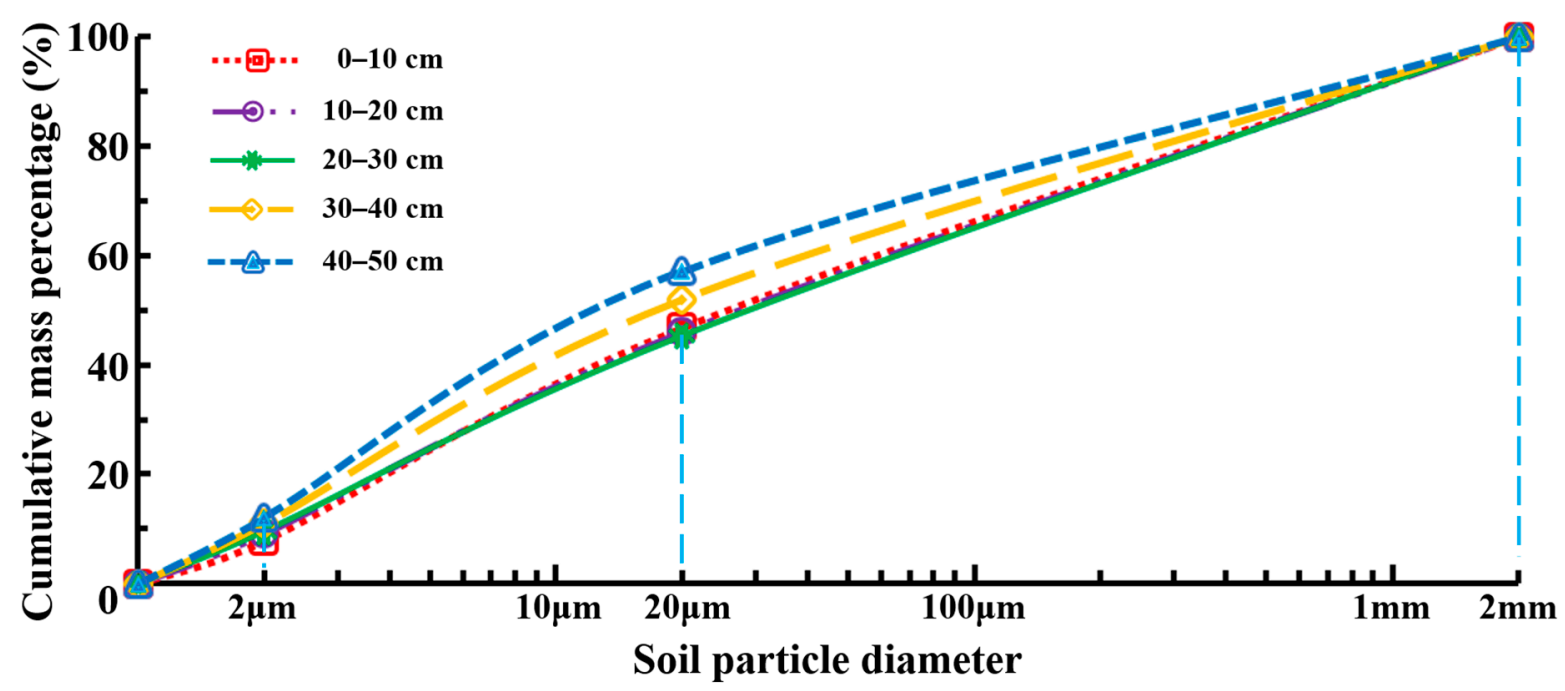

Figure 8. The cumulative mass percentage of soil particle size distribution.

\subsection{Experimental Testing}

According to the tillage range, three operating speeds $(3 \mathrm{~km} / \mathrm{h}, 5 \mathrm{~km} / \mathrm{h}, 7 \mathrm{~km} / \mathrm{h})$ were selected for the field experiments. The operating speed was able to be displayed on the tractor panel and could be controlled by the accelerator pedal and gears, with a subsoiling depth of $30 \mathrm{~cm}$. The tractor ran for $500 \mathrm{~m}$ at each speed, and each test was repeated three 
times. The first $10 \mathrm{~m}$ were used to adjust the tractor working depth and working speed, stable driving distance of $480 \mathrm{~m}$, the vibration frequency of vibration motor in the stable driving area changed evenly with the driving distance, and the last $10 \mathrm{~m}$ gradually reduced the speed and stopped.

\subsection{Measured Values}

\subsubsection{Subsoiling Resistance}

The subsoiling resistance was tested by a traction test system (Figure 6a), a measurement device consisting of an upper suspension sensor, a lower suspension sensor, a data acquisition tool, an inclination sensor and a receiver. The upper and lower suspension sensors were hooked up to three connection points of the tractor. Each sensor had a measurement range of $0-15 \mathrm{kN}$ and a sensitivity of $0.045 \mathrm{kN}$. The sensor input voltage was $24 \mathrm{~V} \mathrm{DC}$, and the output current was $20 \mathrm{~mA}$. The resistance value measured by the sensor was sent to the computer through the wireless mode. The subsoiler was installed on the frame, and the shovel tip was installed on the same standard shovel handle. The subsoiling resistance could be directly transmitted to three mechanical sensors.

\subsubsection{Soil Firmness}

Soil firmness was measured by a firmness meter (Spectrum TDR 300, Chicago, IL, USA), which tested the soil firmness values at the ditch bottom before and after subsoiling and at the transverse $30 \mathrm{~cm}$ from the ditch bottom. The measurement depth was $45 \mathrm{~cm}$, sampled every $25 \mathrm{~mm}$, and five repeated tests were performed for each test.

\section{Results and Discussion}

In this section, the subsoiling resistance values of six shovel tips at three different speeds and different vibration frequencies were compared to verify the resistance reduction effect of vibration and non-smooth surfaces. The total energy consumption of forced vibration subsoiling was analyzed. The changes of soil firmness before and after the subsoiling were compared to assess the effect of subsoiling on soil environment improvement.

\subsection{Analysis of the Subsoiling Resistance}

Figures 9-11 showed the variation of traction force with vibration frequency for six subsoiler tips at $30 \mathrm{~cm}$ depth, at three speeds of $3 \mathrm{~km} / \mathrm{h}, 5 \mathrm{~km} / \mathrm{h}$, and $7 \mathrm{~km} / \mathrm{h}$. In particular, Figure 9 shows the resistance change at $3 \mathrm{~km} / \mathrm{h}$; Figure 10 shows the resistance change at $5 \mathrm{~km} / \mathrm{h}$, and Figure 11 shows the resistance change at $7 \mathrm{~km} / \mathrm{h}$. Five replicate experiments of each data point were carried out, and due to the excessive number of the data points, Figures 9-11 only show the average value of the test points. The resistance data of $0 \mathrm{~Hz}$ was the measured value with the vibration motor inactive, and the other frequency points were obtained with the PWM speed controller. The effect of different parameters on the subsoiling resistance in the field experiment was analyzed below. 


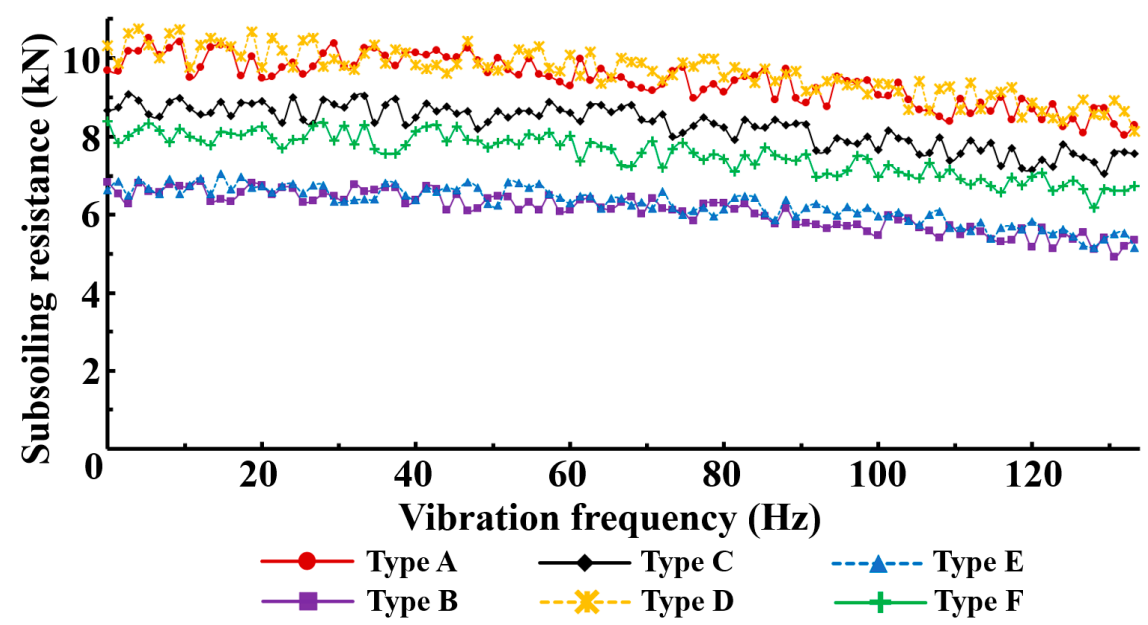

Figure 9. Variation of subsoiling resistance with the vibration frequency of six shovel tips at $3 \mathrm{~km} / \mathrm{h}$ speed.

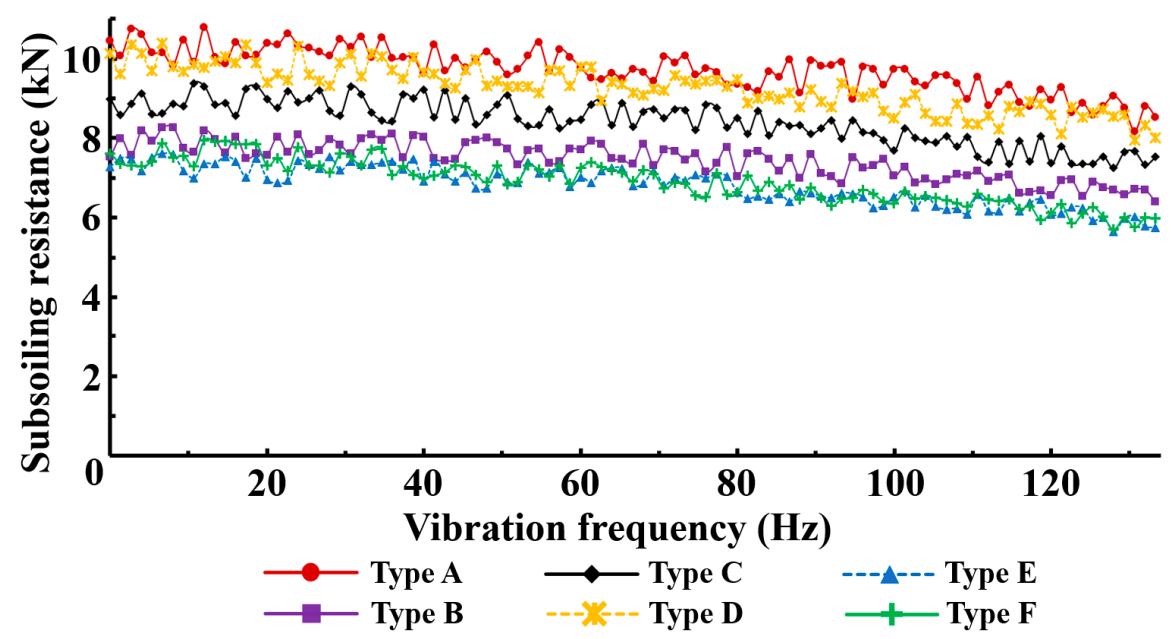

Figure 10. Variation of subsoiling resistance with the vibration frequency of six shovel tips at $5 \mathrm{~km} / \mathrm{h}$ speed.

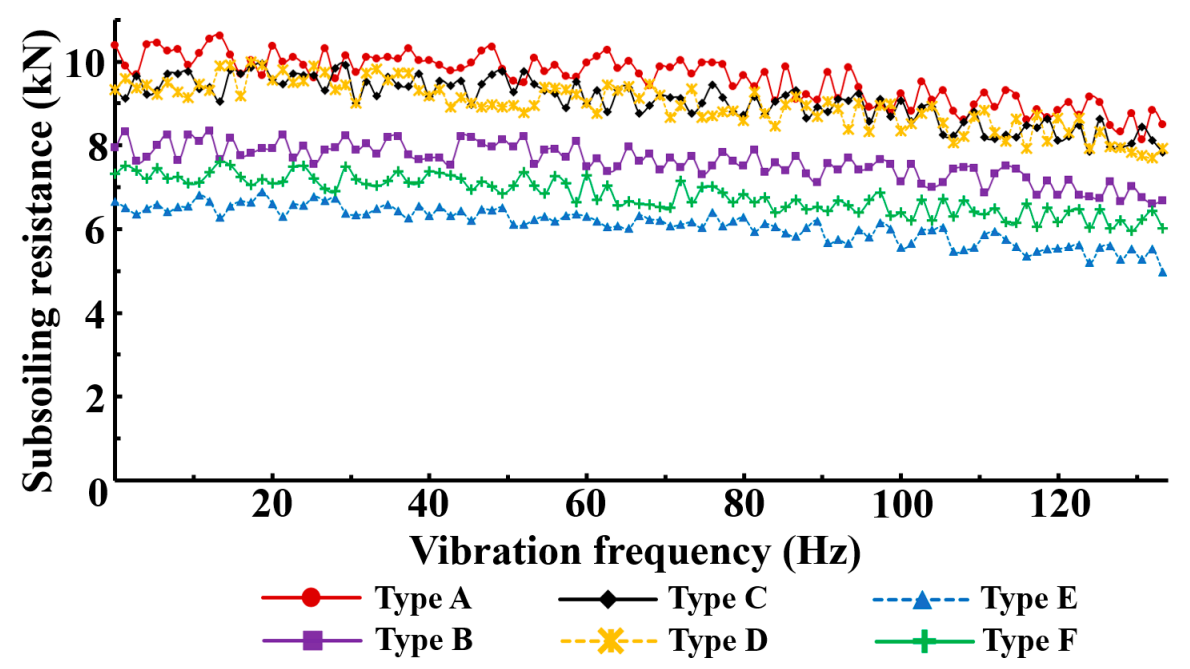

Figure 11. Variation of subsoiling resistance with the vibration frequency of six shovel tips at $7 \mathrm{~km} / \mathrm{h}$ speed. 


\subsubsection{The Effect of Vibration Frequency on Subsoiling Resistance}

Figures 9-11 show the effect of the vibration frequency of forced vibration subsoilers on subsoiling resistance. Under the conditions of six subsoiler tips and three speeds, the vibration subsoiling method could reduce the subsoiling resistance. In the experiment, the higher the vibration frequency was, the smaller the subsoiling resistance was. At the speed of $3 \mathrm{~km} / \mathrm{h}$, compared with no vibration, the maximum resistance reduction rate of subsoiling resistance of six subsoiler tips was $14.9-19.6 \%$. At the speed of $5 \mathrm{~km} / \mathrm{h}$, the maximum resistance reduction rate of six subsoiler tips was $14.5-21.2 \%$. At the speed of $7 \mathrm{~km} / \mathrm{h}$, the maximum resistance reduction rate of the six subsoiler tips was $14.2-17.6 \%$. These experiment results showed that high-frequency vibration could significantly reduce the subsoiling resistance. The superior vibration frequency was higher than the antlion vibration frequency, which might be that this study used PWM to regulate the speed of the vibration motor, and the vibration power was smaller when the frequency was lower. However, the best vibration frequency range needs to be further verified.

\subsubsection{The Effect of Subsoiler Tip Type on Subsoiling Resistance}

The data with vibration frequency above $120 \mathrm{~Hz}$ were summarized. These subsoiling resistances were the smallest at these frequencies, and the variation law of the minimum subsoiling resistances of six subsoiler tips under three speeds was obtained (Figure 12). From the data, it could be observed that the subsoiler tip type had a more significant influence on the subsoiling resistance. Combining the three speeds and comparing shovel tip D, shovel tip E, and shovel tip F, the shovel tip E had the minimum resistance, followed by the shovel tip F, and the shovel tip D had the maximum resistance. Compared with shovel tip D, shovel tip E could reduce resistance by $33.8 \%$ on average, and shovel tip F could reduce resistance by $25.3 \%$. Compared with shovel tip A, shovel tip B could reduce resistance by $29.4 \%$, and shovel tip C could reduce resistance by $10.4 \%$ on average.

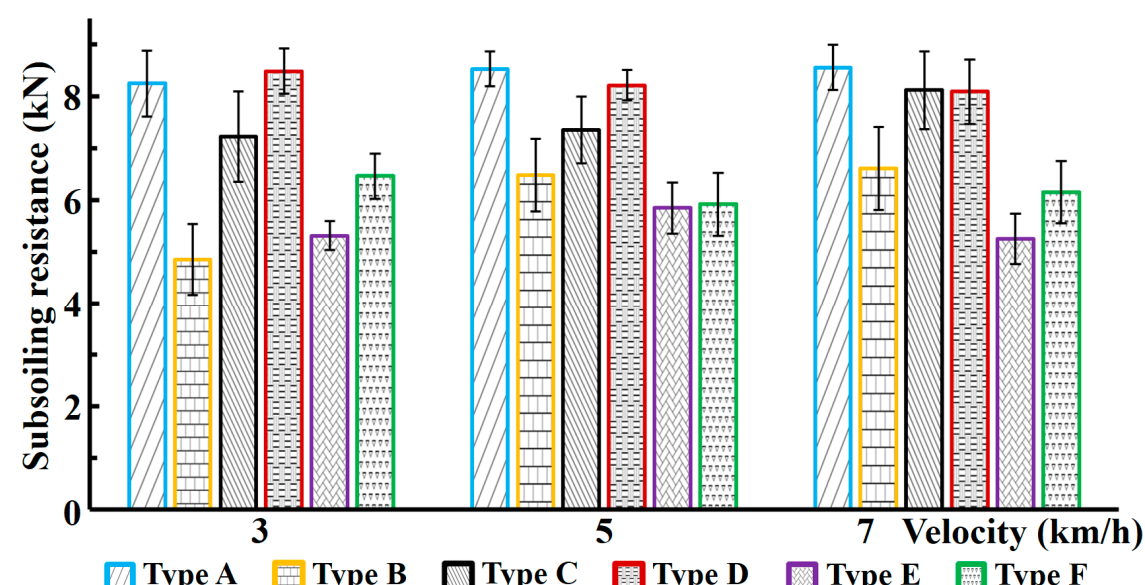

Figure 12. The minimum resistance variation law of vibration subsoiling at three speeds for six subsoiler tips.

In this experiment, the shovel tip E with a non-smooth surface of bionic antlion showed an excellent resistance reduction effect. Because the contact state between soil and the subsoiler surface was changed by means of the surface reshaping, the non-smooth subsoiler tip surface would cause soil particle disturbance during movement so that the soil adhesion force changed from anisotropic to isotropic trend and reduced resistance. Compared with shovel tip E and shovel tip F, both non-smooth surfaces showed better resistance reduction.

Compared with tip D, tip E, tip F and tip A, tip B and tip C, the upper convex surface subsoiler tip had less resistance, and the tip resistance could be reduced by, at most, $24.2 \%$. The up-convex curved shovel tip was able to deflect the soil on both sides during the subsoiling process, making it less likely to form soil nuclear and reducing resistance. The 
results of six types of subsoilers at three speeds and $30 \mathrm{~cm}$ depth conditions showed that the non-smooth surface had a better resistance reduction effect with a maximum resistance reduction rate of $33.8 \%$.

\subsubsection{The Effect of Operation Speed on Subsoiling Resistance}

In this study, with the operating speed increasing, the subsoiling resistance increased slightly, but not significantly. The reason might be that under the soil conditions in this study, the diversion state of the soil on the subsoiler tip face was better, and the extrusion effect of the shovel tip on both sides of the soil was not significantly enhanced when the speed increased, resulting in an unremarkable increase in the subsoiling resistance. Compared with the resistance values of the shovel tip E and the shovel tip F at different speeds, it could be seen that with the speed increasing, the two shovel tips showed a slight decreasing trend of subsoiling resistance, which was due to the fact that with the speed increasing, the non-smooth surface structure could cause more effective soil disturbance and achieve better resistance reduction effect.

\subsection{Energy Consumption Analysis of Forced Vibration Subsoiling}

The forced vibration subsoiling mechanism requires extra energy consumption while vibrating to reduce resistance. When the vibration mechanism is more complex and the frequency is lower, the total energy consumption will increase instead. Assuming that the ratio of total energy consumption of forced vibratory subsoiling to non-vibration energy consumption is $\eta$, then:

$$
\eta=\frac{P_{v i b}}{P_{0}}=\frac{F_{v i b} * v+P_{v s}}{F_{0} * v}
$$

where $P_{v i b}$ is the total energy consumption of the forced vibration, $P_{0}$ is the non-vibration energy consumption, $F_{v i b}$ is the vibration subsoiling resistance, $F_{0}$ is the subsoiling resistance without vibration, $P_{v s}$ is the extra power consumed by the vibration mechanism, and $v$ is the forward speed. When $\eta>1$, the total energy consumption increases, and when $\eta<1$, the total energy consumption decreases, where the reduction rate $r$ can be expressed as $r=1-\eta$.

In this study, according to the analysis of Equation (6), the ratio of total energy consumption of vibrating subsoiling to non-vibration energy consumption at different vibration frequencies was statistically shown in Figures 13-15.

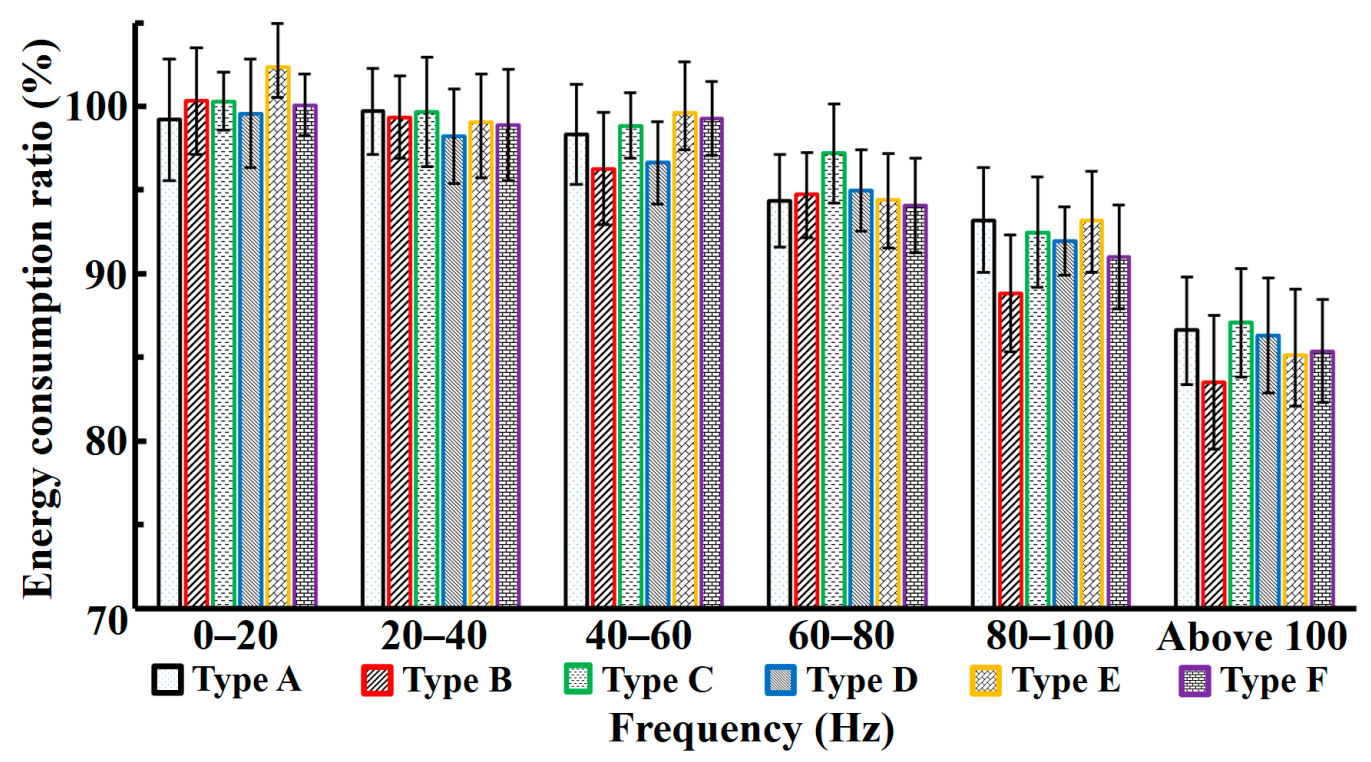

Figure 13. The ratio of forced vibration subsoiling total energy consumption to non-vibration energy consumption at $3 \mathrm{~km} / \mathrm{h}$ speed. 


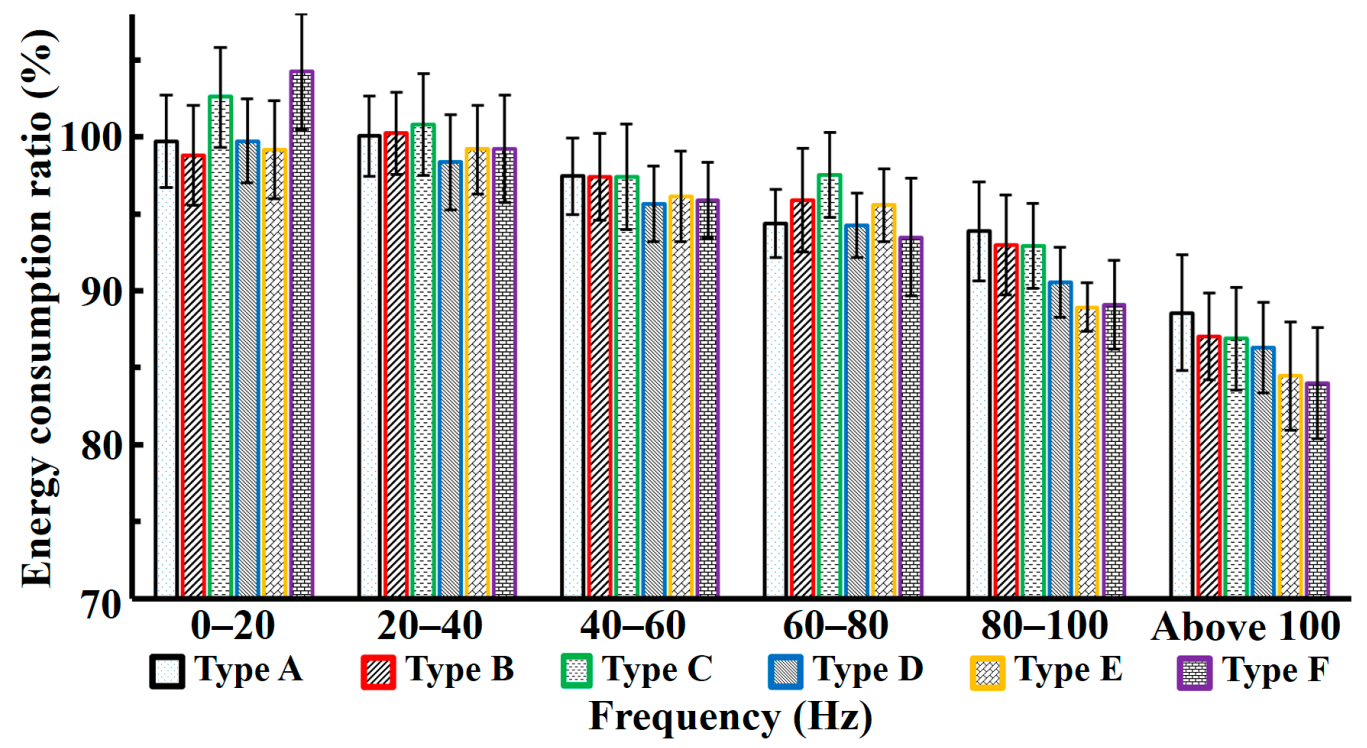

Figure 14. The ratio of forced vibration subsoiling total energy consumption to non-vibration energy consumption at $5 \mathrm{~km} / \mathrm{h}$ speed.

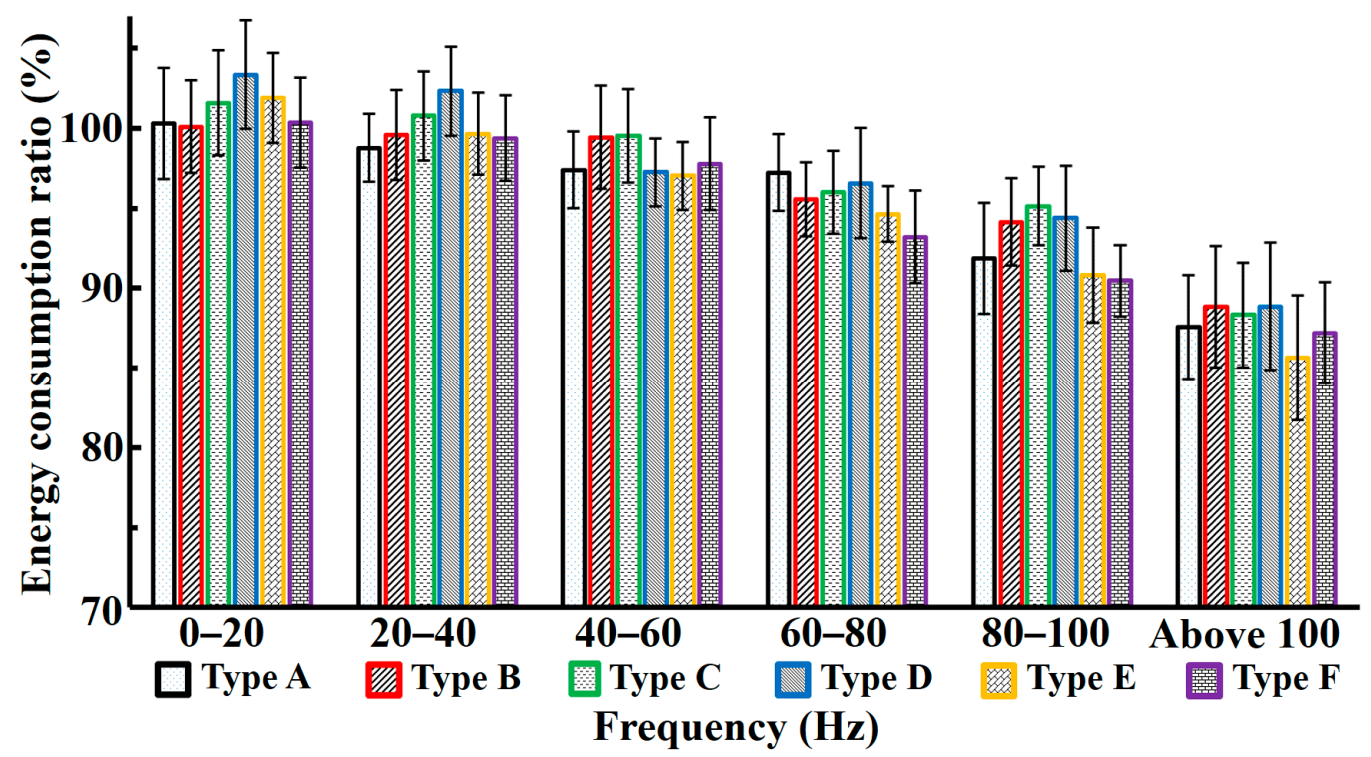

Figure 15. The ratio of forced vibration subsoiling total energy consumption to non-vibration energy consumption at $7 \mathrm{~km} / \mathrm{h}$ speed.

The data in the figures showed that with the increase in vibration frequency, the total energy consumption of vibration subsoiling had a decreasing trend, and when the vibration frequency was in the range of $0-40 \mathrm{~Hz}$, the total energy consumption of vibration subsoiling was not determined compared with no vibration. When the vibration frequency was higher than $40 \mathrm{~Hz}$, the total energy consumption of vibration subsoiling operation was generally lower than that of non-vibration subsoiling operation. When it was higher than $100 \mathrm{~Hz}$, the total energy consumption of vibration subsoiling had the lowest energy consumption ratio to non-vibration. When the forward speed was $3 \mathrm{~km} / \mathrm{h}$, the total energy consumption was reduced by $12.9-16.5 \%$ at maximum. When the speed was $5 \mathrm{~km} / \mathrm{h}$, the total energy consumption was reduced by $11.4-16.0 \%$ at maximum. When the speed was $7 \mathrm{~km} / \mathrm{h}$, the total energy consumption was reduced by $11.2-14.4 \%$ at maximum. Vibration subsoiling showed a good consumption reduction in all three operating speed conditions.

In the prior technology, rigid structures are used, such as crank linkages, cams, eccentric wheels, and so on, in the field of forced vibration subsoiler. These structures 
have big amplitudes and additional energy consumption and are also limited by complex rigid systems, which cannot produce high-frequency vibration. Thus, the frequency is often very low, and the additional energy consumption is very huge. This high-frequency controlled vibration method in this study showed the advantage of reducing resistance and consumption.

\subsection{Changes of Soil Firmness before and after Subsoiling}

The change of soil firmness is one of the important indicators of the subsoiling effect. In this study, in order to verify the effect of vibration subsoiling, shovel tip E was selected, the change of soil firmness before and after subsoiling was tested at $3 \mathrm{~km} / \mathrm{h}$ and $30 \mathrm{~cm}$ depth. The soil firmness showed an increasing trend and then decreased with the increase in depth before subsoiling, the maximum value appeared between $20-30 \mathrm{~cm}$ (Figure 16), and this was the area of the plough pan. The soil firmness values decreased sharply after the subsoiling, and the decrease in soil firmness was most obvious in the bottom of the subsoiling trenches. In this experiment, the interval between two subsoiling was $60 \mathrm{~cm}$, the area with the minimum subsoiling disturbance was $30 \mathrm{~cm}$ laterally from the subsoiling ditch bottom. The soil firmness in this area decreased sharply, indicating that both the vibrating subsoiling and non-vibrating subsoiling had achieved good operating results. Compared with the change of soil firmness of non-vibrating subsoiling (Figure 16a) and that of vibrating subsoiling (Figure 16b), the firmness at the transverse $30 \mathrm{~cm}$ from the subsoiling ditch bottom was slightly greater than that of non-vibrating subsoiling operation. The reason was that it was not easy for the tip of the vibrating subsoiler to form big soil nuclear and avoided greater soil disturbance. This vibration subsoiling method not only achieved the effect of comprehensive subsoiling but also helped to create a soil environment with the combination of loose and compact, which helped to grow crops.
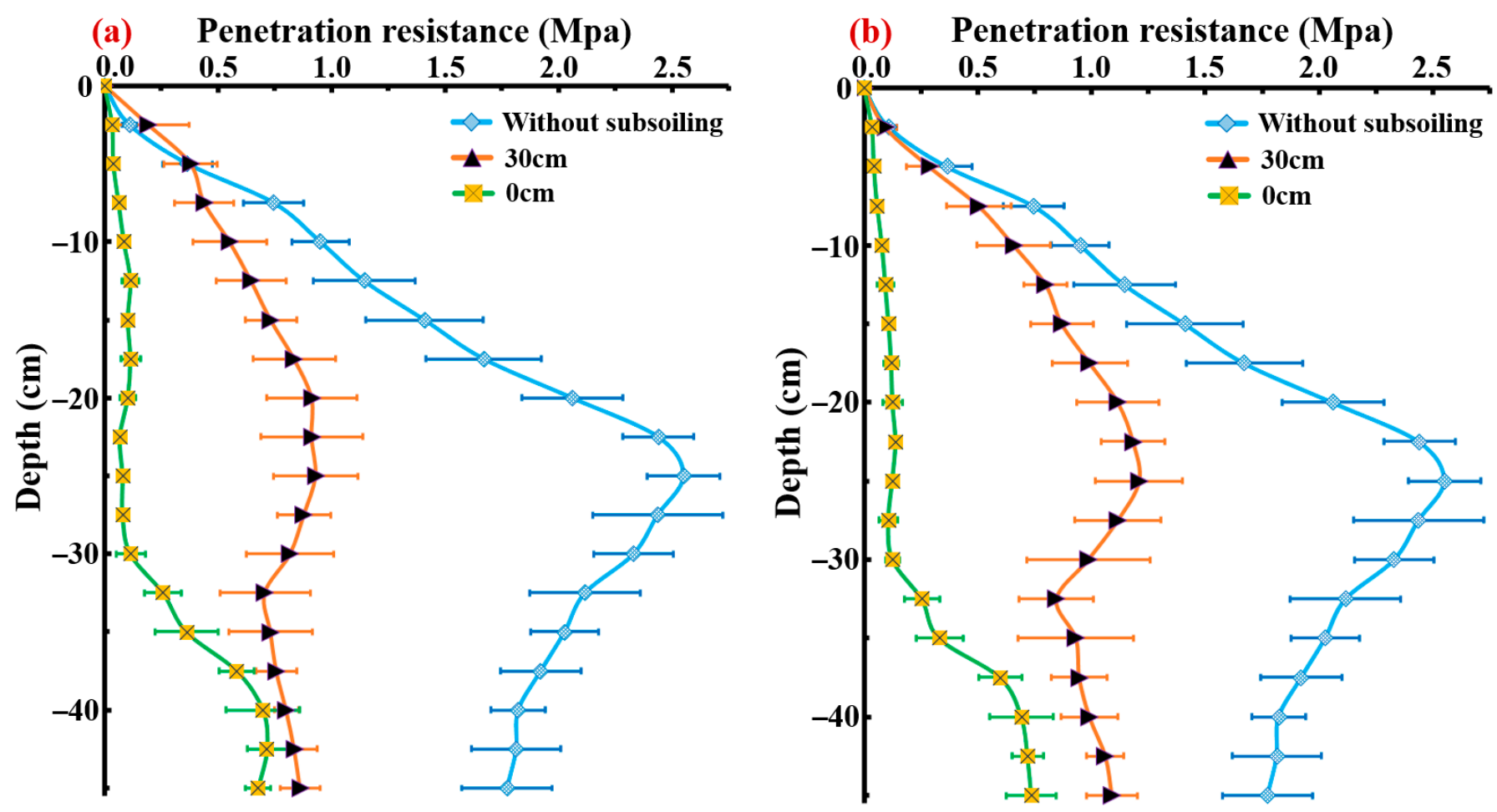

Figure 16. Variation of soil firmness with depth before and after subsoiling: (a) The changes of soil firmness without vibration subsoiling; (b) the changes of soil firmness with vibration subsoiling. 


\section{Conclusions}

This study proposed a new method of vibration resistance reduction for subsoiling soil-touching components. The vibration parameters of the antlions were obtained by a high-speed camera. The vibration and non-smooth surface resistance reduction mechanisms were analyzed. Six types of subsoiler tips were designed, the effect of reducing resistance and consumption was tested by subsoiling experiments in the field. The results showed that the subsoiling resistance decreased with the increase in vibration frequency; the polarized electronic motor vibration subsoiler could not only play the effect of reducing resistance but also reduce the total energy consumption, as well as achieve the full subsoiling effect. The effect of operation speed on subsoiling resistance was not significant, and non-smooth surfaces were able to provide a resistance reduction effect; the subsoiling resistance increased sharply with increasing depth.

The vibration subsoiling could reduce the resistance by $14.2-21.2 \%$ and the total energy consumption by $11.2-16.5 \%$ under the three operating speed conditions. The results from the experimental data demonstrated that the combination of high-frequency vibration and non-smooth surfaces helped to reduce the cohesion of the soil, reduce the angle of internal friction in the soil, destroy the water film layer on the contact surface between the soil-touching components and the soil, change the soil flow state, and reduce the adhesion of the interface layer. This study of the vibrating resistance-reducing method could be applied not only to the design of subsoilers but also to the design of the other soil-touching components to reduce the resistance and consumption.

In further research, we will explore the effect regularity of different vibration parameters on various soil types and further verify the resistance reduction mechanism of vibration and non-smooth surfaces.

Author Contributions: Conceptualization, D.Z. and B.W.; validation, P.H. and Y.X.; writing-original draft, P.H.; writing—review and editing, D.Z. and B.W.; supervision, J.Z., J.T., J.Q., H.Y. and Q.Z. All authors have read and agreed to the published version of the manuscript.

Funding: This work was supported by the Key Projects of Science and Technology Development Plan of Jilin Province, China (Grant no. 20170204015NY); Provincial School Joint Construction Project of Jilin Province, China (Grant no. SXGJXX2017-6); the National Key Research and Development Program of China (Grant nos. 2016YFD070190103 and 2017YFD0701103).

Conflicts of Interest: The authors declare no conflict of interest.

\section{References}

1. Yue, L.; Wang, Y.; Wang, L.; Yao, S.; Cong, C.; Ren, L.; Zhang, B. Impacts of soil compaction and historical soybean variety growth on soil macropore structure. Soil Tillage Res. 2021, 214, 105166. [CrossRef]

2. Cherubin, M.R.; Franchi, M.R.A.; Lima, R.P.; Moraes, M.T.; Luz, F.B. Sugarcane straw effects on soil compaction susceptibility. Soil Tillage Res. 2021, 212, 105066. [CrossRef]

3. Forgó, Z.; Tolvaly-Roșca, F.; Pásztor, J.; Kovari, A. Energy Consumption Evaluation of Active Tillage Machines Using Dynamic Modelling. Appl. Sci. 2021, 11, 6240. [CrossRef]

4. Schneider, F.; Don, A.; Hennings, I.; Schmittmann, O.; Seidel, S.J. The effect of deep tillage on crop yield-What do we really know? Soil Tillage Res. 2017, 174, 193-204. [CrossRef]

5. Zhang, Q.; Yu, L.L.; Jia, H.L.; Liu, X.J.; Zhang, L. Design and Experiments of a Bionic Hook-Shape Subsoiler. Appl. Mech. Mater. 2013, 461, 50-56. [CrossRef]

6. Orzech, K.; Załuski, D. Chemical properties of soil and occurrence of earthworms in soil in response to soil compaction and different soil tillage in cereals. J. Elem. 2020, 25, 153-168. [CrossRef]

7. Li, H.; Zhang, Y.; Zhang, Q.; Ahmad, N.; Liu, P.; Wang, R.; Li, J.; Wang, X. Converting continuous cropping to rotation including subsoiling improves crop yield and prevents soil water deficit: A 12-yr in-situ study in the Loess Plateau, China. Agric. Water Manag. 2021, 256, 107062. [CrossRef]

8. Lal, R. Minimum Tillage Systems; Lewis Publishers: London, UK, 1994.

9. Wang, Y.; Li, N.; Ma, Y.; Tong, J.; Pfleging, W.; Sun, J. Field experiments evaluating a biomimetic shark-inspired (BioS) subsoiler for tillage resistance reduction. Soil Tillage Res. 2020, 196, 104432. [CrossRef]

10. França, J.S.; Reicher, J.M.; Holthusen, D.; Rodrigues, M.F.; Araújo, E.F. Subsoiling and mechanical hole-drilling tillage effects on soil physical properties and initial growth of eucalyptus after eucalyptus on steeplands. Soil Tillage Res. 2021, 207 , 104860. [CrossRef] 
11. Wang, H.; Bai, W.; Han, W.; Song, J.; Lv, G. Effect of subsoiling on soil properties and winter wheat grain yield. Soil Use Manag. 2019, 35, 643-652. [CrossRef]

12. Zhang, X.C.; Guo, J.; Ma, Y.F.; Yu, X.F.; Hou, H.Z.; Wang, H.L.; Fang, Y.J.; Tang, Y.F. Effects of vertical rotary subsoiling with plastic mulching on soil water availability and potato yield on a semiarid Loess plateau, China. Soil Tillage Res. 2020, $199,104591$. [CrossRef]

13. Zhang, Y.; Wang, S.; Wang, H.; Wang, R.; Wang, X.; Li, J. Crop yield and soil properties of dryland winter wheat-spring maize rotation in response to 10-year fertilization and conservation tillage practices on the Loess Plateau. Field Crop Res. 2018, 225, 170-179. [CrossRef]

14. Scarpare, F.V.; Quirijn, D.J.V.L.; De, C.L.; Pires, R.C.M.; Ruiz-Corrêa, S.T.; Bezerra, A.H.F.; Gava, G.J.C.; Dias, C.T.S. Tillage effects on soil physical condition and root growth associated with sugarcane water availability. Soil Tillage Res. 2019, 187, 110-118. [CrossRef]

15. Wang, Y.; Osman, A.; Zhang, D.; Yang, L.; Cui, T.; Zhong, X. Optimized design and field experiment of a staggered vibrating subsoiler for conservation tillage. Int. J. Agric. Biol. Eng. 2019, 12, 59-65. [CrossRef]

16. Sun, J.; Wang, Y.; Ma, Y.; Tong, J.; Zhang, Z. DEM simulation of bionic subsoilers (tillage depth $>40 \mathrm{~cm}$ ) with drag reduction and lower soil disturbance characteristics. Adv. Eng. Softw. 2018, 119, 30-37. [CrossRef]

17. Ma, X.; Wang, S.; Wang, H. Vibration Soil Crushing Mechanism of Self-excited Vibration Subsoiler in Coastal Area. J. Coast. Res. 2020, 103, 426-430. [CrossRef]

18. Li, J.; Jiang, X.; Ma, Y.; Tong, J.; Hu, B. Bionic Design of a Potato Digging Shovel with Drag Reduction Based on the Discrete Element Method (DEM) in Clay Soil. Appl. Sci. 2020, 10, 7096. [CrossRef]

19. Wang, Y.; Xue, W.; Ma, Y.; Tong, J.; Liu, X.; Sun, J. DEM and soil bin study on a biomimetic disc furrow opener. Comput. Electron. Agric. 2019, 156, 209-216. [CrossRef]

20. Sun, J.; Wang, Y.; Zhang, S.; Ma, Y.; Tong, J.; Zhang, Z. The mechanism of resistance-reducing/anti-adhesion and its application on biomimetic disc furrow opener. Math. Biosci. Eng. 2020, 17, 4657-4677. [CrossRef]

21. Wang, Y.; Zhang, D.; Yang, L.; Cui, T.; Jing, H.; Zhong, X. Modeling the interaction of soil and a vibrating subsoiler using the discrete element method. Comput. Electron. Agric. 2020, 174, 105518. [CrossRef]

22. Hilal, Y.Y.; Al-rajabo, S.A.J.; Dahham, G.A. The effects of vibrating wings subsoiler plow on driver's seat of agricultural tractors and mechanization performance. Soil Tillage Res. 2021, 205, 104806. [CrossRef]

23. Zheng, K.; McHugh, A.; Li, H.; Wang, Q.; Lu, C.; Hu, H.; Liu, W.; Zhang, Z.; Liu, P.; He, J. Design and experiment of anti-vibrating and anti-wrapping rotary components for subsoiler cum rotary tiller. Int. J. Agric. Biol. 2019, 12, 47-55. [CrossRef]

24. Wang, Y.; Zhang, D.; Yang, L.; Cui, T.; Zhang, W.; Qi, B.; Li, Y.; Zhong, X. Field performance of an electric-hydraulic control system for vibrating subsoiler with flexible tines. Comput. Electron. Agric. 2020, 172, 105377. [CrossRef]

25. Zhang, X.; Wang, C.; Chen, Z.; Zeng, Z. Design and experiment of a bionic vibratory subsoiler for banana fields in southern China. Int. J. Agric. Biol. 2016, 9, 75-83.

26. Ma, X.; Wang, S. Design and Study on Vibration Characteristics of Self-excited Vibration Layered Subsoiler for Coastal Soil. J. Coastal Res. 2020, 103, 318-322. [CrossRef]

27. Büsse, S.; Büscher, T.H.; Gorb, S.N.; Stutz, H.H. Sand-throwing behaviour in pit-building antlion larvae: Insights from finiteelement modelling. J. R. Soc. Interface 2021, 18, 1742-5662. [CrossRef]

28. Farji-Brener, A.G.; Juncosa-Polzella, A.S.; Tejada, D.M.; Centeno-Alvarado, D.; Hernández-Soto, M.; Soto-Huaira, M.; GutiérrezCruz, S. Disadvantages of living in a populous neighborhood for sit-and-wait predators: Competition for space reduces pit-trap size in antlion larvae. Ethology 2020, 126, 1031-1037. [CrossRef]

29. Miler, K.; Yahya, B.; Czarnoleski, M. Substrate moisture, particle size and temperature preferences of trap-building larvae of sympatric antlions and wormlions from the rainforest of Borneo. Ecol. Entomol. 2019, 44, 488-493. [CrossRef]

30. Tong, J.; Wu, B.; Song, Z.; Gao, Z.; Sun, J.; Ma, Y.; Zhuang, J. Research on the Drag Reduction Mechanism of Antlion (Myrmeleon Sagax) Larvae Nonsmooth Structural Surface. Microsc. Res. Tech. 2020, 83, 338-344. [CrossRef]

31. Wu, A.X.; Sun, Y.Z.; Liu, X.P. Basic Physical and Mechanical Properties of Granules; Metallurgical Industry Press: Beijing, China, 2002.

32. Ren, L.Q. Soil Adhesion Mechanics; Machinery Industry Press: Beijing, China, 2011.

33. Rafiei Renani, H.; Martin, C.D. Slope Stability Analysis using Equivalent Mohr-Coulomb and Hoek-Brown criteria. Rock Mech. Rock Eng. 2020, 53, 13-21. [CrossRef]

34. Moran, D.A.; Pantelides, C.P. Elliptical and circular FRP-confined concrete sections: A Mohr-Coulomb analytical model. Int. J. Solids Struct. 2012, 49, 881-898. [CrossRef]

35. Wu, B.G. Research of Forced Vibration and Structure Coupling Biomimetic Subsoiler for Energy Saving and Drag Reduction. Ph.D. Thesis, Jilin University, Cangchun, China, 2020.

36. FAO, IUSS. World Reference Base for Soil Resources 2014. International Soil Classification System for Naming Soils and Creating Legends for Soil Maps; FAO, IUSS: Rome, Italy, 2015; p. 203. 